\begin{abstract}
Migration patterns of the northern subpopulation of the Pacific sardine (Sardinops sagax) were examined by using parasites as biological tags. This approach has been employed on marine fish species worldwide, but it had not yet been used to investigate the migratory behavior of this ecologically and commercially valuable species in the California Current. In 2005-2008, 14 taxa of parasites were recovered from 1388 Pacific sardine collected between British Columbia, Canada, and Southern California. The results of multivariate analyses indicate significant differences in parasite communities among all size classes of Pacific sardine caught off Vancouver Island, British Columbia, compared with those caught off Washington and Oregon and regions off California. Significant differences in parasite communities also were identified between size classes of Pacific sardine: $<210,210$ 219 , and $\geq 220 \mathrm{~mm}$ in standard length. Our results support a high degree of residency in all size categories of Pacific sardine off Vancouver Island during the study period, and they indicate that individual sardine behavior is not limited to completing an annual migration between British Columbia or the Pacific Northwest and Southern California. These data indicate that using parasites as biological tags could help clarify annual migration patterns of individual Pacific sardine.
\end{abstract}

Manuscript submitted 10 September 2018. Manuscript accepted 26 July 2019. Fish. Bull. 117:196-210 (2019). Online publication date: 15 August 2019. doi: 10.7755/FB.117.3.7

The views and opinions expressed or implied in this article are those of the author (or authors) and do not necessarily reflect the position of the National Marine Fisheries Service, NOAA.

\title{
Use of parasites to clarify residency and migration patterns of Pacific sardine (Sardinops sagax) in the California Current
}

\author{
Kym Jacobson (contact author) ${ }^{1}$ \\ Rebecca Baldwin ${ }^{2}$ \\ Michael Banks ${ }^{2}$ \\ Robert Emmett ${ }^{1}$ \\ Email address for contact author: kym.jacobson@noaa.gov \\ ${ }^{1}$ Newport Research Station \\ Northwest Fisheries Science Center \\ National Marine Fisheries Service, NOAA \\ 2032 SE OSU Drive \\ Newport, Oregon 97365 \\ ${ }^{2}$ Cooperative Institute for Marine Resources Studies \\ Hatfield Marine Science Center \\ Oregon State University \\ 2030 SE Marine Science Drive \\ Newport, Oregon 97365
}

The Pacific sardine (Sardinops sagax) is an ecologically important pelagic fish in upwelling systems that transfers energy from lower trophic levels (phytoplankton and zooplankton) to upper trophic predators, including fish, marine mammals, and birds (Cury et al., 2000). The Pacific sardine fishery is also economically important, providing for bait, aquaculture feed, and human consumption (Herrick et al., 2009). In the 1930s and 1940s, the Pacific sardine fishery in the California Current was the largest fishery in the Western Hemisphere (reviewed in Wolf, 1992). The fishery collapsed and was closed off the Pacific Northwest (PNW, Oregon and Washington) in 1947 and off Central California in 1967 (Radovich, 1981). Heavily influenced by ocean conditions, the biomass of the Pacific sardine in the California Current System (CCS) fluctuates widely. After a substantial biomass increase in the late 1980s and 1990s (Hargreaves et al., 1994; Emmett et al., 2005), a purse seine fishery reopened in
California, the PNW, and off Vancouver Island in British Columbia, Canada, followed by a formal closure in 2015 .

Three subpopulations of the Pacific sardine are currently recognized in the CCS (reviewed in Smith, 2005). One spawns in the Gulf of California, one spawns in inshore waters of southern Baja California, Mexico, and a northern subpopulation spawns primarily off Southern and Central California. For the management of Pacific sardine, the governments of both the United States and Canada assume all Pacific sardine of the northern subpopulation belong to one northerly migrating stock (Hill et al. ${ }^{1}$ ). Pacific sardine have also spawned successfully further north in some years, indicating either a possible separate spawning population

\footnotetext{
${ }^{1}$ Hill, K. T., P. R. Crone, E. Dorval, and B. J. Macewicz. 2015. Assessment of the Pacific sardine resource in 2015 for U.S.A. management in 2015-16, 116 p. Agenda item G.1.a. Pacific Fish. Manage. Counc., Portland, OR. [Available from website.]
} 
or repeated spawning by migrants (Emmett et al., 2005; Lo et al., 2010). If the Pacific sardine commercially landed off British Columbia is from a portion of the northern subpopulation that does not return to California to spawn in certain years, it could have management considerations for how quotas are determined for both Canada and the United States.

The results of tagging studies conducted between 1936 and 1942, during the peak of the California fishery, indicate that Pacific sardine routinely migrated from spawning grounds off San Diego, California, to feeding grounds off the PNW and Vancouver Island (Hart, 1943; Clark and Janssen, 1945). In recent years, without a sufficient biomass or a reduction fishery to collect tags, repeating largescale tagging studies has not been feasible. Financial costs of such studies have been prohibitive because thousands of tagged fish are needed to increase the probability of recovery of tagged individuals (Jacobsen and Hansen, 2005).

The recent use of techniques to examine potential stock discrimination and migration patterns of the northern stock, such as genetics (Hedgecock et al., 1989; Lecomte et al., 2004), size composition (Lo et al., 2011), otolith morphometrics (Javor et al., 2011; Javor, 2013), and stable oxygen isotopic signatures (Javor and Dorval, 2014), have had mixed results. No genetic differences have been identified between the Pacific sardine captured in any region of the CCS (Hedgecock et al., 1989; Lecomte et al., 2004). Lo et al. (2011) used biomass estimates of different size classes to estimate migration of different size classes between the PNW and California in 2003-2005. Otolith morphometrics differentiated age-1 Pacific sardine collected from Monterey, California, from those collected off San Diego in 2006-2007 (Javor et al., 2011). Stable oxygen isotopic signatures of otoliths showed some north-south trends for juvenile Pacific sardine but no regional differentiation among otoliths of adult Pacific sardine (Javor and Dorval, 2014).

One method that has successfully identified or confirmed migration patterns and stocks of marine fish species worldwide is the use of parasite species as biological tags (Thomas et al., 1996; MacKenzie and Abaunza, 1998; MacKenzie, 2002). Many parasite taxa can serve as biological tags because a fish can become infected with a parasite only within that parasite's endemic area (where all conditions for transmission exist). The presence of a parasite in a fish host caught outside of that parasite's endemic area, therefore, indicates that the fish host had previously been in the parasite's endemic area. Parasites of fish can be acquired by direct transmission or through trophic transmission, meaning the consumption of infected prey including crustaceans and other fish. Once in a fish host, parasites can be relatively long lived, remaining in or on the host from months to years, depending on the host-parasite association (Rohde, 1984). The technique of using parasites has limitations, such as time-consuming examination of hosts for internal parasites, a potential need for molecular techniques for correct identification, and a lack of adequate information on a parasite's ecology and biology (reviewed in MacKenzie and Abaunza, 1998, 2014). Despite these limitations, this technique has often been used by scientific and fisheries agencies (Pita et al., 2016), and by 2014 more than 290 peer-reviewed manuscripts had been published on the topic (Timi and MacKenzie, 2015).

The objective of our research was to determine if parasites infecting the northern stock of Pacific sardine could be used to identify migration patterns of the northern stock of Pacific sardine within the CCS. Our approach included comparing 1) the parasite communities of Pacific sardine collected from 5 regions along the west coast of North America and 2) the parasite communities of Pacific sardine to those of the central and northern subpopulations of non-migratory northern anchovy (Engraulis mordax), which are infected with many of the same parasite species (Love and Moser, 1983; Zorica et al., 2015). The parasites of northern anchovy could help confirm distributions of parasites recovered from migratory Pacific sardine in the northern CCS.

\section{Materials and methods}

\section{Fish samples}

From March through November 2005-2008, 1388 Pacific sardine were opportunistically collected by research and commercial fishing personnel in the CCS, between Vancouver Island $\left(32^{\circ}\right.$ to $\left.51^{\circ} \mathrm{N}\right)$ and Southern California $\left(119-128^{\circ} \mathrm{W}\right.$ ) (Fig. 1). Pacific sardine from British Columbia were caught with a modified Cantrawl ${ }^{2}$ (Cantrawl Nets Ltd., Richmond, Canada), a model 240-rope trawl (for details, see Morris et al. ${ }^{3}$ ). All other Pacific sardine and northern anchovy (except for northern anchovy collected off Southern California with a seine net) were caught using a Nordic 264-rope trawl (for details, see Baldwin et al., 2008). Fish collected for this study were immediately frozen onboard the vessel and later stored at $-80^{\circ} \mathrm{C}$ in the laboratory until processed for parasites.

Pacific sardine ranged in size from 100.6 to $285.7 \mathrm{~mm}$ fresh standard length (SL). Of 1388 collected specimens, 562 fish were classified as non-migrants ( $<200 \mathrm{~mm} \mathrm{SL})$ and 826 fish were classified as migrants ( $\geq 200 \mathrm{~mm} \mathrm{SL}$ ) (Table 1 ). Following Lo et al. (2011), Pacific sardine $<200 \mathrm{~mm}$ SL are non-migratory. Therefore, we hypothesized that parasite communities in this size category of Pacific sardine would differ among regions of the CCS. In contrast, migratorysized Pacific sardine ( $\geq 200 \mathrm{~mm}$ SL) would have similar parasite communities throughout the CCS, if the entire population of the northern stock was migrating annually from Southern or Central California to British Columbia and then returning to California to spawn.

\footnotetext{
${ }^{2}$ Mention of trade names or commercial companies is for identification purposes only and does not imply endorsement by the National Marine Fisheries Service, NOAA.

${ }^{3}$ Morris, J. F. T., M. Trudel, M. E. Thiess, T. B. Zubowski, H. R. Maclean, J. M. R. Curtis, and L. Felli. 2009. CCGS W.E. Ricker Gulf of Alaska salmon survey, June 20-July 5, 2007. Dep. Fish. Oceans, Can. Data Rep. Fish. Aquat. Sci. 1221, 178 p. [Available from website.]
} 


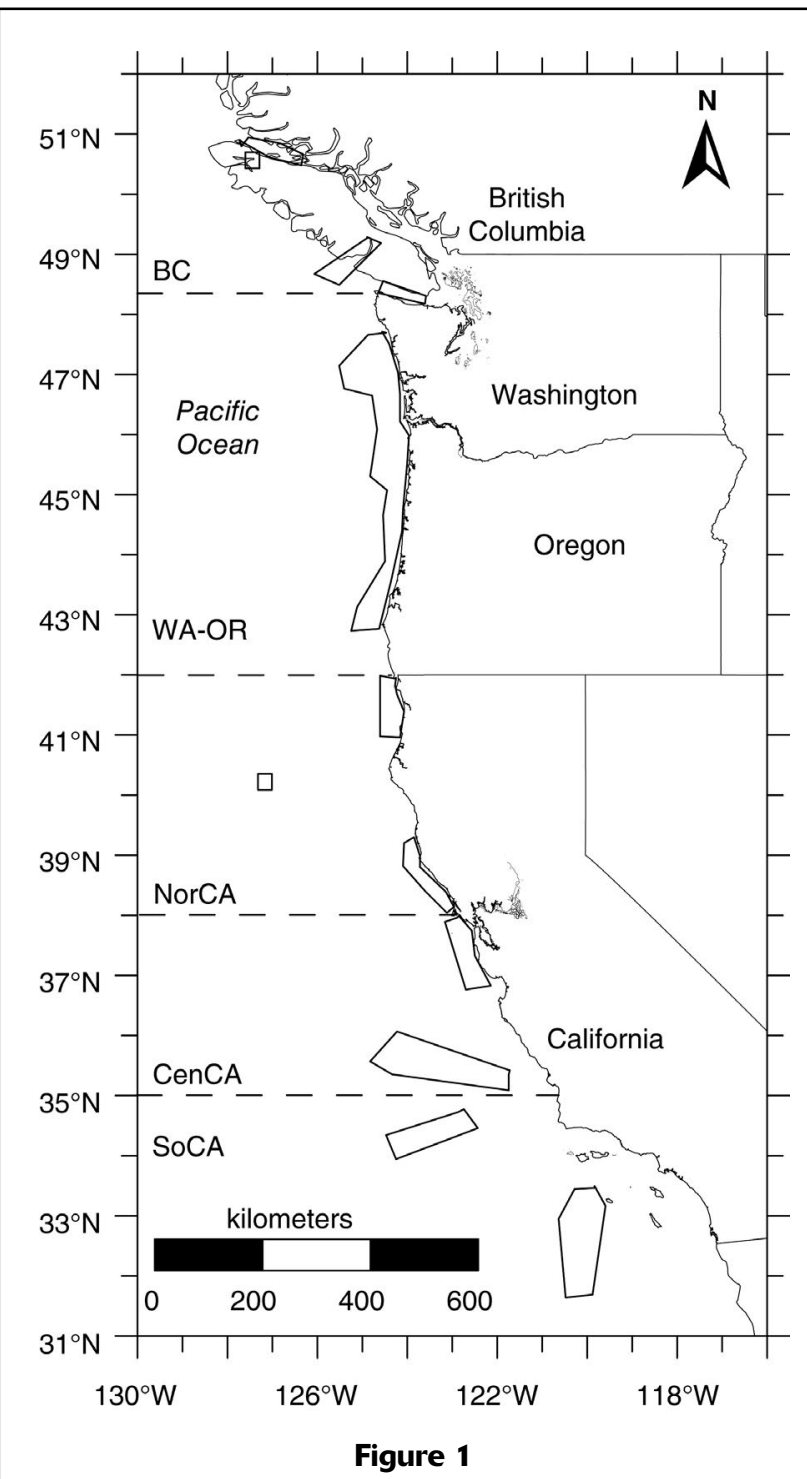

Map of the 5 regions of the California Current System where Pacific sardine (Sardinops sagax) were sampled from 2005 through 2008 for analyses of parasite communities. The regions are Vancouver Island, British Columbia (BC), Canada, Washington and Oregon (WA-OR), Northern California (NorCA), Central California (CenCA), and Southern California (SoCA). Boxes outlined with a black line represent areas within each region in which opportunistic samples were taken.

Although not all Pacific sardine were aged, we estimated ages to vary from 0 to 10 years, on the basis of Hill et al. (2010) and by using a relationship between age and SL (Javor ${ }^{4}$ ). A subset of the Pacific sardine caught off California during this period was aged. The median age of this subset ranged from 2 years in 2005 and 2006 to 3 years and 4 years in 2007 and 2008 (Dorval et al., 2015).

\footnotetext{
${ }^{4}$ Javor, B. 2008. Personal commun. Southwest Fish. Sci. Cent., Natl. Mar. Fish. Serv., 8901 La Jolla Shores Dr., La Jolla, CA 92037.
}

However, analyses did not focus on fish age because it was not possible to age all individual Pacific sardine in our study.

During 2007 and 2008, 168 northern anchovy (98.0-143.0 mm SL) were collected to serve as nonmigratory sample controls. In June-July 2007, 20 northern anchovy (104-125 mm SL) were collected off Grays Harbor, Washington $\left(47.00^{\circ} \mathrm{N}\right)$, and 97 fish $(100-143 \mathrm{~mm}$ SL) were captured off Willapa Bay, Washington $\left(46.67^{\circ} \mathrm{N}\right)$. In June 2008, 51 northern anchovy (98-142 mm SL) were collected off Point Hueneme, California $\left(34.15^{\circ} \mathrm{N}\right)$.

Each fish was thawed in the laboratory, weighed to the nearest $0.1 \mathrm{~g}$, and measured (as SL in millimeters). To account for shrinkage due to freezing, lengths of thawed Pacific sardine were adjusted by using the following regression (Lo et al., 2007):

$$
\text { Fresh } S L=2.89+1.0286(\text { Thawed } S L) .
$$

No length regression formula was available for the northern anchovy to estimate fresh SL; therefore, SL values are reported from fish that were frozen and then thawed.

\section{Parasite recovery}

Standard necropsy procedures were followed to examine fish for parasites (Arthur and Albert, 1994; Baldwin and Goater, 2003), with the body cavity and external surface of the viscera examined for parasites during removal of the stomach and intestine. Gills were examined only in Pacific sardine caught in 2005 because only one unknown monogenean was recovered from gills examined in 2005. Eyes were also not examined because no parasites were recovered from the eyes of Pacific sardine by us in a previous study; nor were they reported in other studies in the CCS (Love and Moser, 1983). When possible, recovered parasites were identified morphologically to species by using dissection and compound microscopes; then they were preserved in $95 \%$ ethanol. Most parasites were identified to species, but those in poor condition were classified only to phylum or class. Because we found no difference in geographic distributions among 5 anisakid nematode taxa from a subset of these Pacific sardine in a previous study (Baldwin et al., 2011), all anisakids (identified genetically or morphologically) were combined into one category for this study and referred to herein as Anisakis spp.

\section{Statistical analyses}

We divide the study area of the CCS into 5 regions to best define where fish were sampled: 1) Vancouver Island (hereafter, referred to as British Columbia (from $52.0^{\circ} \mathrm{N}$ to $\left.48.3^{\circ} \mathrm{N}\right), 2$ ) Washington and Oregon $\left(48.3^{\circ} \mathrm{N}\right.$ to $\left.42.0^{\circ} \mathrm{N}\right)$, 3) Northern California (from the Oregon-California border at $42.0^{\circ} \mathrm{N}$ to $\left.\left.38.0^{\circ} \mathrm{N}\right), 4\right)$ Central California $\left(38.0^{\circ} \mathrm{N}\right.$ to $35.0^{\circ} \mathrm{N}$ ), and 5) Southern California (south of $35.0^{\circ} \mathrm{N}$ to $32.0^{\circ} \mathrm{N}$ ) (Fig. 1). We describe the parasite communities as defined by Bush et al. (1997) by using parasite prevalence (the percentage of infected fish) and mean intensity (the number of individual parasites per infected fish). 
Because Lo et al. (2011) reported different migration rates (estimated percentages of the total biomass) of the northern subpopulation of Pacific sardine on the basis of size, we initially analyzed non-migrant Pacific sardine ( $<200 \mathrm{~mm}$ SL) and different size categories of potential migrants separately. Pacific sardine $\geq 200 \mathrm{~mm}$ SL (potential migrants) were split into 3 size categories: 200-209, 210-219, and $\geq 220 \mathrm{~mm}$ SL.

We used multivariate methods to explore variation in the parasite community data. Multivariate analyses of parasite communities were performed by using the multivariate statistics package PRIMER, vers. 7 (PRIMER-e Ltd., Auckland, New Zealand) (Clarke and Gorley, 2015) that includes the PERMANOVA+ module (Anderson et al., 2008). Only infected fish were included in multivariate analyses. Sample sizes of infected Pacific sardine per size category per region are provided in Table 2. Some individual fish harbored few parasites; therefore, parasite intensity data were averaged among $3-5$ fish with the greatest similarity in length. Parasite intensity data were squareroot transformed to reduce skewness due to any dominant parasite species and to stabilize the variance (Clarke et al., 2014a). Unidentifiable parasites (41 of the 2451 parasites recovered, $<2 \%$ of the total) were not included in the multivariate analysis.

We constructed resemblance matrices based upon Bray-Curtis similarity with a dummy parasite value of 1 included to reduce the variability of some of the sparsely infected samples (Clarke et al., 2006). We then used these matrices to construct nonmetric multidimensional scaling (MDS) ordinations on region $\times$ fish size centroids to graphically explore spatial patterns of differences among the parasite communities of fish groups (Clarke et al., 2014a).

To quantitatively evaluate variation in parasite communities, multivariate parasite data were modeled for main effects by using a 3-way permutational multivariate analysis of variance (PERMANOVA) based on Bray-Curtis similarities (Bray and Curtis, 1957). The PERMANOVA test applies a nonparametric discriminative method based on permutation tests that do not rely on assumptions (e.g., normality, equal variance) commonly too stringent for most ecological data sets (Anderson, 2001). Main factors in the model include region, fish size category, and haul nested in region as a random factor. Year was included as a random factor in the initial model, but it was not a significant factor and was removed. The models were run for 9999

\section{Table 1}

General information on Pacific sardine (Sardinops sagax) classified as either non-migratory ( $<200 \mathrm{~mm}$ in standard length [SL]) or migratory ( $\geq 200 \mathrm{~mm} \mathrm{SL}$ ). Fish were caught by using a modified rope trawl or purse seine in 5 regions of the California Current System from 2005 through 2008 and analyzed for parasites. $\mathrm{H}=$ total number of hauls; $n=$ number of fish caught; and $\mathrm{SE}=$ standard error.

\begin{tabular}{|c|c|c|c|c|c|c|c|c|c|}
\hline \multirow[b]{3}{*}{ Region } & \multirow[b]{3}{*}{$\mathrm{H}$} & \multicolumn{8}{|c|}{ Mean SL } \\
\hline & & \multicolumn{4}{|c|}{$<200 \mathrm{~mm}$} & \multicolumn{4}{|c|}{$\geq 200 \mathrm{~mm}$} \\
\hline & & $n$ & Years & (SE) & Min. & $n$ & Years & (SE) & Max. \\
\hline Vancouver Island, Canada & 6 & 43 & $05-07$ & $175.8(2.68)$ & 148.1 & 176 & $05-07$ & $223.1(1.14)$ & 285.7 \\
\hline Washington and Oregon & 19 & 113 & $05-07$ & $184.6(1.55)$ & 100.6 & 419 & $05-08$ & $219.4(0.83)$ & 279.6 \\
\hline Northern California & 10 & 142 & $06-07$ & $191.8(0.78)$ & 120.2 & 139 & $06-07$ & $208.2(0.82)$ & 260.4 \\
\hline Central California & 5 & 152 & $05-07$ & $175.4(1.23)$ & 106.8 & 36 & $06-07$ & $211.3(1.88)$ & 267.2 \\
\hline Southern California & 4 & 112 & $06-07$ & $178.3(0.93)$ & 157.2 & 56 & $06-08$ & $220.8(1.53)$ & 257.9 \\
\hline
\end{tabular}

\section{Table 2}

Number of Pacific sardine (Sardinops sagax) caught from 2005 through 2008 in 5 regions of the California Current System and infected with at least 1 parasite to be included in multivariate community analyses. $\mathrm{SL}=$ standard length.

\begin{tabular}{lccccrc}
\hline $\begin{array}{l}\text { Size category } \\
(\mathrm{mm} \text { SL) }\end{array}$ & $\begin{array}{c}\text { British } \\
\text { Columbia }\end{array}$ & $\begin{array}{c}\text { Washington and } \\
\text { Oregon }\end{array}$ & $\begin{array}{c}\text { Northern } \\
\text { California }\end{array}$ & $\begin{array}{c}\text { Central } \\
\text { California }\end{array}$ & $\begin{array}{c}\text { Southern } \\
\text { California }\end{array}$ & Total \\
\hline$<200$ & 29 & 40 & 87 & 79 & 87 & 322 \\
$200-209$ & 20 & 55 & 59 & 7 & 7 & 148 \\
$210-219$ & 40 & 72 & 13 & 11 & 9 & 145 \\
$\geq 220$ & 78 & 101 & 6 & 2 & 21 & 208 \\
Total & 167 & 268 & 165 & 99 & 124 & 823 \\
& & & & & & \\
\hline
\end{tabular}


permutations. The PERMANOVA $F$-ratio test statistic is based on the expectations of mean squares and is directly analogous to the construction of the $F$-statistic for multifactorial univariate models but should be thought of as a pseudo $F$-test statistic because it does not have a known distribution under a true null hypothesis (Anderson et al., 2008). To estimate statistical significance between regions and between size categories, pairwise PERMANOVA tests were run. These tests included a Type II (conditional) sum of squares, with fixed effects summed to zero for mixed terms, and permutation of residuals under a reduced model. The pairwise PERMANOVA pseudo $t$-test statistic is a direct multivariate analogue to the univariate $t$-statistic (Anderson et al., 2008). Exact permutation $P$-values are reported.

Canonical analysis of principal coordinates (CAP) was used to further examine differences among parasite communities by measuring the distinctiveness of groups through cross validation (Anderson et al., 2008). Overparameterization was prevented by choosing the number of principal coordinate analysis (PCO) axes that maximized a leave-one-out allocation success to groups (Anderson and Robinson, 2003). The CAP analyses were based on abundance data and used a Bray-Curtis dissimilarity coefficient. A permutation "trace" $(t r)$ test (sum of squared canonical eigenvalues) was used to test for significant differences.
We determined which parasite taxa contributed the greatest percent contributions to distinctiveness of parasite communities by using the similarity percentage (SIMPER) procedure in PRIMER and performed a shade plot analysis (Clarke et al., 2014b) on the 7 most abundant parasite taxa to provide a visual display of the parasite taxa most responsible for differences or trends among sizes of Pacific sardine and regions of collection.

For the parasite communities of northern anchovy, for which a less complex data set was available, a one-way multivariate analysis of similarities (ANOSIM) permutation test was used to identify differences in parasite mean abundances among regions. The ANOSIM test, based on rank similarities, provides $R$ values. An $R$ value close to or equal to one indicates that all communities within a group are more similar to each other than to communities from different groups, and an $R$ value approximating zero indicates that similarities within and between groups are the same (Clarke and Green, 1988).

\section{Results}

\section{Pacific sardine: parasite taxa recovered}

A total of 14 trophically transmitted parasite taxa were recovered from Pacific sardine (Table 3). We recovered

\section{Table 3}

Prevalence (P) and mean intensity (I), with 95\% confidence intervals (95\% CIs), of parasites recovered from 1388 Pacific sardine (Sardinops sagax) caught in 5 regions of the California Current System from 2005 through 2008. $n=$ sample size. Asterisks $(*)$ denote that only 2 infected fish were collected.

\begin{tabular}{|c|c|c|c|c|c|c|c|c|c|c|}
\hline \multirow[b]{2}{*}{ Parasite taxa } & \multicolumn{2}{|c|}{$\begin{array}{c}\text { British } \\
\text { Columbia }(n=219)\end{array}$} & \multicolumn{2}{|c|}{$\begin{array}{l}\text { Washington and } \\
\text { Oregon }(n=532)\end{array}$} & \multicolumn{2}{|c|}{$\begin{array}{l}\text { Northern California } \\
\qquad(n=281)\end{array}$} & \multicolumn{2}{|c|}{$\begin{array}{c}\text { Central California } \\
\quad(n=188)\end{array}$} & \multicolumn{2}{|c|}{$\begin{array}{l}\text { Southern California } \\
\qquad(n=168)\end{array}$} \\
\hline & $\mathrm{P}(\%)$ & $\mathrm{I}(95 \% \mathrm{CI})$ & $\mathrm{P}(\%)$ & $\mathrm{I}(95 \% \mathrm{CI})$ & $\mathrm{P}(\%)$ & $\mathrm{I}(95 \% \mathrm{CI})$ & $\mathrm{P}(\%)$ & I $(95 \% \mathrm{CI})$ & $\mathrm{P}(\%)$ & $\mathrm{I}(95 \% \mathrm{CI})$ \\
\hline \multicolumn{11}{|l|}{ NEMATODA } \\
\hline Anisakis spp. & 25.1 & $1.4(1.2-1.6)$ & 24.2 & $1.7(1.4-2.0)$ & 11.4 & $1.0(0.9-1.1)$ & 6.4 & $1.3(0.7-1.6)$ & 12.0 & $2.3(1.3-3.3)$ \\
\hline $\begin{array}{l}\text { Contracaecum } \\
\text { margolisi }\end{array}$ & 0.0 & & 0.0 & & 0.0 & & 0.0 & & 1.2 & $1.5^{*}$ \\
\hline C. rudolphii & 0.0 & & 0.0 & & 0.0 & & 0.0 & & 1.8 & 1.0 \\
\hline Hysterothylacium sp. & 18.7 & $1.3(1.1-1.5)$ & 19.0 & $1.5(1.3-1.7)$ & 24.9 & $1.4(1.2-1.6)$ & 9.6 & $1.2(0.9-1.5)$ & 31.5 & $1.5(1.3-1.7)$ \\
\hline Unknown nematode & 0.9 & 1.0 & 2.4 & $1.2(1.0-1.4)$ & 3.2 & $1.2(0.9-1.5)$ & 2.1 & 1.0 & 3.0 & 1.0 \\
\hline \multicolumn{11}{|l|}{ TREMATODA } \\
\hline Lampritrema sp. & 0.0 & & 0.0 & & 0.0 & & 0.5 & 1.0 & 0.0 & \\
\hline Lecithaster gibbosus & 48.4 & $4.9(3.7-6.1)$ & 8.1 & $2.9(1.8-3.0)$ & 1.1 & 1.0 & 0.0 & & 0.0 & \\
\hline Myosaccium ecaude & 5.0 & $1.6(0.6-2.6)$ & 8.1 & $1.2(0.8-1.6)$ & 28.8 & $2.2(1.6-3.0)$ & 29.8 & $2.1(1.6-2.6)$ & 41.7 & $2.3(1.5-3.1)$ \\
\hline Parahemiurus merus & 25.1 & $1.8(1.4-2.2)$ & 5.3 & $1.0(0.9-1.1)$ & 5.3 & $1.3(0.9-1.7)$ & 16.0 & $1.1(0.9-1.3)$ & 19.0 & $1.3(1.1-1.5)$ \\
\hline Pronoprymna petrowi & 8.7 & $7.0(2.8-11.2)$ & 0.4 & $1.5^{*}$ & 0.0 & & 0.0 & & 0.0 & \\
\hline Unknown trematode & 0.5 & 1.0 & 0.0 & & 0.4 & 1.0 & 0.0 & & 0.6 & 1.0 \\
\hline \multicolumn{11}{|l|}{ ACANTHOCEPHALA } \\
\hline Rhadinorhynchus sp. & 0.5 & 2.0 & 1.9 & $1.3(0.9-1.7)$ & 0.7 & 1.0 & 1.6 & 1.0 & 1.8 & 1.0 \\
\hline \multicolumn{11}{|l|}{ CESTODA } \\
\hline Tetraphyllidea & 0.0 & & 0.2 & 1.0 & 0.0 & & 0.0 & & 0.0 & \\
\hline Unknown cestode & 0.5 & 5.0 & 0.0 & & 0.0 & & 0.0 & & 0.0 & \\
\hline
\end{tabular}


parasites from $59.3 \%$ of the Pacific sardine sampled. The prevalence of infection (percentage of samples infected) of any parasite taxa ranged from less than $1.0 \%$ to $48.4 \%$, and mean intensities of infection ranged from 1.0 to 7.0 individual parasites of a taxon per infected fish (Table 3).

The most abundant parasite (greatest prevalence and intensity) recovered from the Pacific sardine from any region was the trematode Lecithaster gibbosus. Its prevalence was highest in Pacific sardine caught off British Columbia at $48.4 \%$ infected. The highest intensity of L. gibbosus was 51 individual parasites in a single Pacific sardine caught off British Columbia. Although abundant in the north, this parasite was not recovered from any Pacific sardine caught off Central or Southern California. Another commonly recovered trematode, Myosaccium ecaude, was found at a high prevalence of $41.7 \%$ off Southern California, as well as at relatively high prevalences off Central and Northern California (29.8\% and $28.8 \%$, respectively). This trematode was also recovered in the region off Washington and Oregon and off British Columbia but at prevalences of only $8.1 \%$ and $5.0 \%$, respectively.

Nematodes from 2 genera, Hysterothylacium sp. and Anisakis spp., were also recovered at relatively high prevalences (but low intensities) throughout the study area (Table 3). Hysterothylacium sp. was recovered in highest prevalence $(31.5 \%)$ in Southern California. Anisakis spp. were recovered in highest prevalence off British Columbia and in the region off Washington and Oregon ( $25.1 \%$ and $24.2 \%$, respectively), but mean intensity was slightly higher for Anisakis spp. in Southern California.

\section{Northern anchovy: parasite taxa recovered and distribution patterns}

A total of 7 parasite taxa were recovered from the northern anchovy (Table 4). Parasites were recovered from $60 \%$ of the northern anchovy caught off Grays Harbor, Washington, $21 \%$ of fish caught off Willapa Bay, Washington, and $69 \%$ of fish caught off Port Hueneme, California. Mean intensities of all parasite taxa were low, ranging from 1.0 to 2.0 individual parasites per infected anchovy. Although the nematodes Anisakis spp. and Hysterothylacium sp. were recovered from northern anchovy from all 3 locations, the parasite communities were significantly different (ANOSIM: global $R=0.88, P<0.01$ ). The trematode Parahemiurus merus was also found in all locations but at higher prevalence off Southern California at 33\% infected, compared with $5 \%$ and $2 \%$ in both northern groups. An unidentified trematode belonging to the Didymozoidae was recovered exclusively from northern anchovy collected off Southern California at a prevalence of $41 \%$. In contrast, the trematode $L$. gibbosus was recovered exclusively, and at a high prevalence of $45 \%$, from the most northern samples collected off Grays Harbor. Pairwise ANOSIM showed that the parasite communities from the two collections of anchovy from different locations off Washington were also significantly different (ANOSIM: $R=0.75, P=0.01$ ).

\section{Multivariate community analyses: parasites of Pacific sardine}

A nonmetric MDS ordination of parasite community data averaged by size category and region shows the differences in parasite communities of all size categories of Pacific sardine from British Columbia compared with

\section{Table 4}

Prevalence $(\mathrm{P})$ and mean intensity (I), with 95\% confidence intervals (95\% CI), of parasites recovered from northern anchovy (Engraulis mordax) caught off Washington (WA) in 2007 and Southern California (CA) in 2008. $n=$ sample size. An asterisk (*) denotes that only 2 infected fish were collected.

\begin{tabular}{|c|c|c|c|c|c|c|}
\hline \multirow[b]{2}{*}{ Parasite taxa } & \multicolumn{2}{|c|}{$\begin{array}{l}\text { Grays Harbor, WA } \\
\qquad(n=20)\end{array}$} & \multicolumn{2}{|c|}{$\begin{array}{c}\text { Willapa Bay, WA } \\
\qquad(n=97)\end{array}$} & \multicolumn{2}{|c|}{$\begin{array}{l}\text { Port Hueneme, CA } \\
\qquad(n=51)\end{array}$} \\
\hline & $\mathrm{P}(\%)$ & I $(95 \% \mathrm{CI})$ & $\mathrm{P}(\%)$ & I $(95 \%$ CI $)$ & $\mathrm{P} \%$ & $\mathrm{I}(95 \% \mathrm{CI})$ \\
\hline \multicolumn{7}{|l|}{ NEMATODA } \\
\hline Anisakis spp. & 10.0 & $1.5^{*}$ & 5.2 & 1.0 & 5.9 & 1.0 \\
\hline Hysterothylacium sp. & 5.0 & 1.0 & 7.2 & $1.3(0.8-1.8)$ & 17.6 & $1.2(0.7-1.7)$ \\
\hline Unknown nematode & 0.0 & & 11.3 & $1.3(0.9-1.7)$ & 10.0 & $1.2(0.6-1.8)$ \\
\hline \multicolumn{7}{|l|}{ TREMATODA } \\
\hline Lecithaster gibbosus & 45.0 & $2.0(0.8-3.2)$ & 0.0 & & 0.0 & \\
\hline Parahemiurus merus & 5.0 & 1.0 & 2.1 & 1.0 & 33.3 & $1.3(1.1-1.5)$ \\
\hline Didymozoidae & 0.0 & & 0.0 & & 41.2 & $1.8(1.2-2.2)$ \\
\hline \multicolumn{7}{|l|}{ CESTODA } \\
\hline Tetraphyllidea & 5.0 & 1.00 & 0.0 & & 0.0 & \\
\hline
\end{tabular}


those from all size categories from all other regions (Fig. 2A). This nonmetric MDS plot also shows the trend of the differences in parasite communities among size categories of Pacific sardine within each region, except for those from Central and Southern California.

An additional nonmetric MDS ordination includes the parasite communities of the 3 northern anchovy collections with those of Pacific sardine (Fig. 2B). Figure 2B shows the high similarity of the parasite community of northern anchovy collected off Grays Harbor to those of Pacific sardine collected off British Columbia. The parasite community of northern anchovy collected off Willapa Bay was most similar to parasite communities of Pacific sardine 200-209 and 210-219 mm SL from Washington and Oregon and of Pacific sardine 210-219 mm SL from Northern and Central California. The sample of northern anchovy collected off Port Hueneme was most similar to Pacific sardine 200-209 mm SL collected off Southern California. The overlays on this nonmetric MDS plot show clustering of all parasite communities south of British Columbia at $60 \%$ similarity and clustering in 4 groups of parasite communities at $70 \%$ similarity. The 4 groups are composed of communities recovered from 1) Pacific sardine from British Columbia and northern anchovy from off Grays Harbor, 2) northern anchovy from Southern California and Pacific sardine 200-209 mm SL from Southern California, 3) Pacific sardine $<200 \mathrm{~mm}$ SL from all California regions and Pacific sardine 200-209 mm SL from Central California, and 4) all Pacific sardine collected from Washington and Oregon, Pacific sardine 200-209 mm SL from Northern California, all Pacific sardine 210-219 mm SL and $\geq 220 \mathrm{~mm}$ SL from California, and northern anchovy from Willapa Bay.

A 2-way PERMANOVA on Pacific sardine parasite communities showed that both region (pseudo- $F=4.75$ ) and fish size category (pseudo- $F=5.12)$ were significant factors $(P<0.01)$ in the main effects model. There was not a significant interaction between region and fish size (pseudo- $F=0.97, P=0.50$ ). A PERMANOVA for pairwise comparison of parasite communities showed that there was no significant difference between the parasite communities of Pacific sardine $<200 \mathrm{~mm}$ SL and 200-209 $\mathrm{mm}$ SL (pseudo $t=1.43, P=0.11$ ) (data not shown). Thus, these size categories were combined into one category $(<210 \mathrm{~mm} \mathrm{SL})$ in further analyses. In contrast, parasite communities from the 2 larger size categories were significantly different from those of the smaller Pacific sardine and from each other (all comparisons $P<0.05$ ) (data not shown).

Pairwise regional comparisons with PERMANOVA between the parasite communities
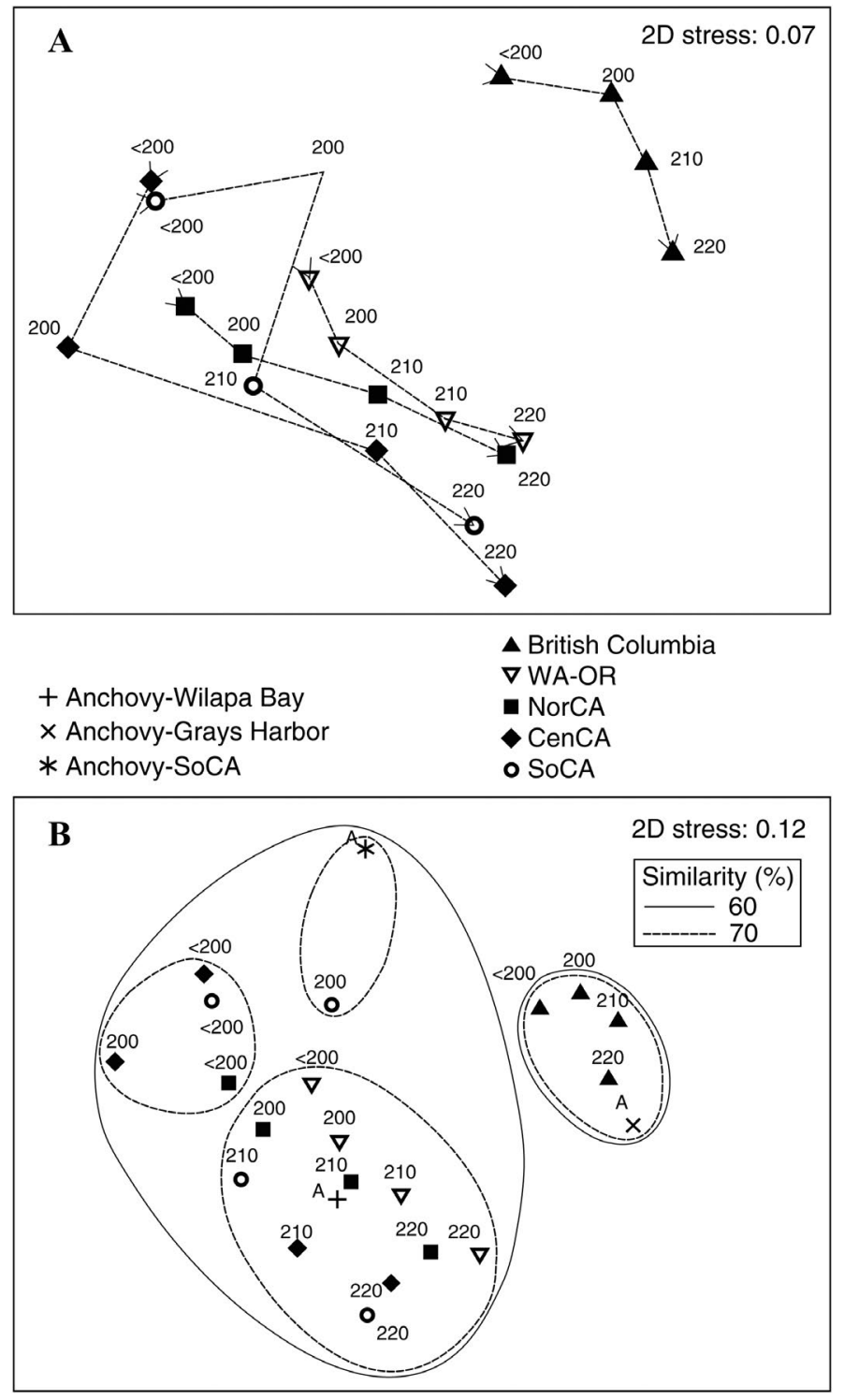

Figure 2

Nonmetric multidimensional scaling (MDS) plots of distance from centroids calculated from square-root transformed data of parasite abundance from (A) Pacific sardine (Sardinops sagax) sampled in the California Current System from 2005 through 2008, averaged by size category and region of collection (lines connect size categories within a region), and (B) Pacific sardine caught in 2005-2008 and northern anchovy (Engraulis mordax) caught off Washington in 2007 (2 sites) and Southern California in 2008 ( 1 site), averaged by collection location. Results of a hierarchical agglomerative clustering with similarity values of $60 \%$ and $70 \%$ are overlaid onto the plot. Symbol shapes represent regions where Pacific sardine were sampled. Sample collection occurred in 5 regions: Vancouver Island, British Columbia, Canada, Washington and Oregon (WA-OR); Northern California (NorCA), Central California (CenCA), and Southern California (SoCA). The labels $<200,200,210$, and 220 indicate the size category: <200, 200-209, $210-219$, and $\geq 220 \mathrm{~mm}$ in standard length. The $2 \mathrm{D}$ stress value is a measure of the representation of interrelationships in a 2-dimensional ordination space, with stress $<0.1$ corresponding to a good interpretation and stress $<0.2$ providing a useful 2 -dimensional picture. 
of Pacific sardine from the 5 different regions were analyzed separately for the different size categories, following the results of the pairwise comparison on size categories described above. For Pacific sardine $<210 \mathrm{~mm}$ SL (the combination of the 2 smallest size categories), the parasite communities collected off British Columbia were significantly different from those from all other sampled regions of the CCS (all comparisons: $P<0.01$ ) (Table 5). No other regional comparisons were statistically significant for this size category of Pacific sardine. For Pacific sardine 210$219 \mathrm{~mm}$ SL, the parasite communities of fish from British Columbia were significantly different from those collected off Washington and Oregon (pseudo- $t=2.41, P<0.01$ ) and off Northern California (pseudo- $t=1.89, P=0.01) . P$-values for pairwise regional comparisons with PERMANOVA between Pacific sardine in this size category from British Columbia and Central and Southern California were 0.08. For Pacific sardine $\geq 220 \mathrm{~mm}$ SL, a significant difference between parasite communities was found between fish caught off British Columbia and those collected off Washington and Oregon (pseudo- $t=1.71, P=0.04$ ) (Table 5).

Because the pairwise PERMANOVA for regions showed no differences among our regions of California, we performed a CAP analysis with those regions condensed into one California region. The CAP analysis further supported significant differences among all regions for the Pacific sardine $<210 \mathrm{~mm}$ SL $(t r=0.63182, P=0.0001)$. The selected orthonormal PCO axes ( $m=3$ axes) described $89 \%$ of the variation in the data cloud. Cross-validation results of this CAP model show the distinctiveness of the Pacific sardine $<210 \mathrm{~mm}$ SL collected off British Columbia with correct allocation to their own group at $76.5 \%$ and of the Pacific sardine $<210 \mathrm{~mm}$ SL collected off California with correct allocation to California at $82.2 \%$ (Table 6). Similar results of CAP analysis were observed with Pacific sardine 210-219 mm SL ( $t r=0.67626, P=0.0001)$ and $\geq 220 \mathrm{~mm}$ SL ( $t r=0.50237, P=0.0001)$. Correct allocations to British Columbia were $80 \%$ and $70 \%$ for these 2 size categories of large Pacific sardine when the $m=3$ and $m=4$ orthonormal PCO axes, respectively, were used. The correct allocation of Pacific sardine $\geq 220 \mathrm{~mm}$ SL back to California was also high at $80 \%$. Correct allocations to Washington and Oregon were fewer, with assignments also going to both British Columbia and California, but were greater than the $33.3 \%$ that would be expected from chance alone, except for fish $\geq 220 \mathrm{~mm}$ SL (Table 6 ).

Regional differences in abundance of specific parasites observed among Pacific sardine played a differential role in defining regional parasite communities. For example, 3 trematode species, L. gibossus, Pronoprymna petrowi, and Parahemiurus merus, were more abundant in samples from British Columbia than in those from other regions (see shade differences presented in Figure 3). In contrast, another trematode, $M$. ecaude, had high abundance in Pacific sardine from California regions. Abundance of Anisakis spp. increased in concert with increasing size of Pacific sardine from all regions, but especially among large sardines collected off Central and Southern California.

In all size categories of Pacific sardine caught off British Columbia, the trematode $L$. gibossus provided the highest percent contribution to the parasite communities, from $71.5 \%$ in the Pacific sardine $<210 \mathrm{~mm}$ SL to

\section{Table 5}

Results of pairwise comparisons with permutational multivariate analysis of variance (PERMANOVA) between parasite communities of Pacific sardine (Sardinops sagax) caught from 2005 through 2008 in 5 regions of the California Current System and analyzed separately by size category: $<210 \mathrm{~mm}$ standard length (SL), 210-219 $\mathrm{mm}$ SL, and $\geq 220 \mathrm{~mm}$ SL. The regions are British Columbia (1), Washington and Oregon (2), Northern California (3), Central California (4), and Southern California (5). The pairwise PERMANOVA pseudo- $t$ test statistic is a direct multivariate analogue to the univariate $t$-statistic. This value is provided with a permutation $P$-value.

\begin{tabular}{|c|c|c|c|c|c|c|}
\hline \multirow[b]{2}{*}{$\begin{array}{l}\text { Regional } \\
\text { comparisons }\end{array}$} & \multicolumn{2}{|c|}{$<210 \mathrm{~mm} \mathrm{SL}$} & \multicolumn{2}{|c|}{ 210-219 mm SL } & \multicolumn{2}{|c|}{$\geq 220 \mathrm{~mm} \mathrm{SL}$} \\
\hline & Pseudo- $t$ & $\begin{array}{c}P \\
\text { (perm) }\end{array}$ & Pseudo- $t$ & $\begin{array}{c}P \\
\text { (perm) }\end{array}$ & Pseudo- $t$ & $\begin{array}{c}P \\
\text { (perm) }\end{array}$ \\
\hline 1,2 & 2.60 & $<0.01$ & 2.41 & $<0.01$ & 1.71 & 0.04 \\
\hline 1,3 & 3.69 & $<0.01$ & 1.89 & 0.01 & 1.50 & 0.12 \\
\hline 1,4 & 3.08 & $<0.01$ & 1.52 & 0.08 & 1.36 & 0.20 \\
\hline 1,5 & 2.85 & $<0.01$ & 1.67 & 0.08 & 1.40 & 0.95 \\
\hline 2,3 & 1.32 & 0.17 & 0.59 & 0.77 & 0.38 & 0.95 \\
\hline 2,4 & 1.25 & 0.06 & 0.75 & 0.55 & 0.47 & 0.83 \\
\hline 2,5 & 1.66 & 0.22 & 1.18 & 0.24 & 0.53 & 0.75 \\
\hline 3,4 & 1.36 & 0.17 & 0.77 & 0.66 & 0.60 & 0.75 \\
\hline 3,5 & 1.35 & 0.17 & 0.85 & 0.67 & 0.71 & 0.50 \\
\hline 4,5 & 0.81 & 0.50 & 0.57 & 0.90 & 0.63 & 0.85 \\
\hline
\end{tabular}




\section{Table 6}

Percentage of correct allocations of parasite communities of Pacific sardine (Sardinops sagax), caught from 2005 through 2008, to 3 regions of the California Current System based on cross-validation results of canonical analysis of principal coordinates. SL=standard length.

\begin{tabular}{|c|c|c|c|c|c|c|}
\hline Collection location & $\begin{array}{l}\text { Size category } \\
\quad(\mathrm{mm} \mathrm{SL})\end{array}$ & $\begin{array}{l}\text { British } \\
\text { Columbia }\end{array}$ & $\begin{array}{l}\text { Washington } \\
\text { and Oregon }\end{array}$ & California & $\begin{array}{l}\text { No. of sample } \\
\text { groups }\end{array}$ & $\begin{array}{c}\% \\
\text { correct }\end{array}$ \\
\hline \multirow[t]{3}{*}{ British Columbia } & $<210$ & 13 & 3 & 1 & 17 & 76.5 \\
\hline & $210-219$ & 8 & 1 & 1 & 10 & 80.0 \\
\hline & $\geq 220$ & 14 & 5 & 1 & 20 & 70.0 \\
\hline \multirow[t]{3}{*}{ Washington and Oregon } & $<210$ & 5 & 15 & 14 & 34 & 44.1 \\
\hline & $210-219$ & 2 & 12 & 10 & 24 & 50.0 \\
\hline & $\geq 220$ & 8 & 9 & 12 & 29 & 31.0 \\
\hline \multirow[t]{3}{*}{ California } & $<210$ & 0 & 18 & 83 & 101 & 82.2 \\
\hline & $210-219$ & 1 & 5 & 5 & 11 & 45.5 \\
\hline & $\geq 220$ & 0 & 2 & 8 & 10 & 80.0 \\
\hline
\end{tabular}

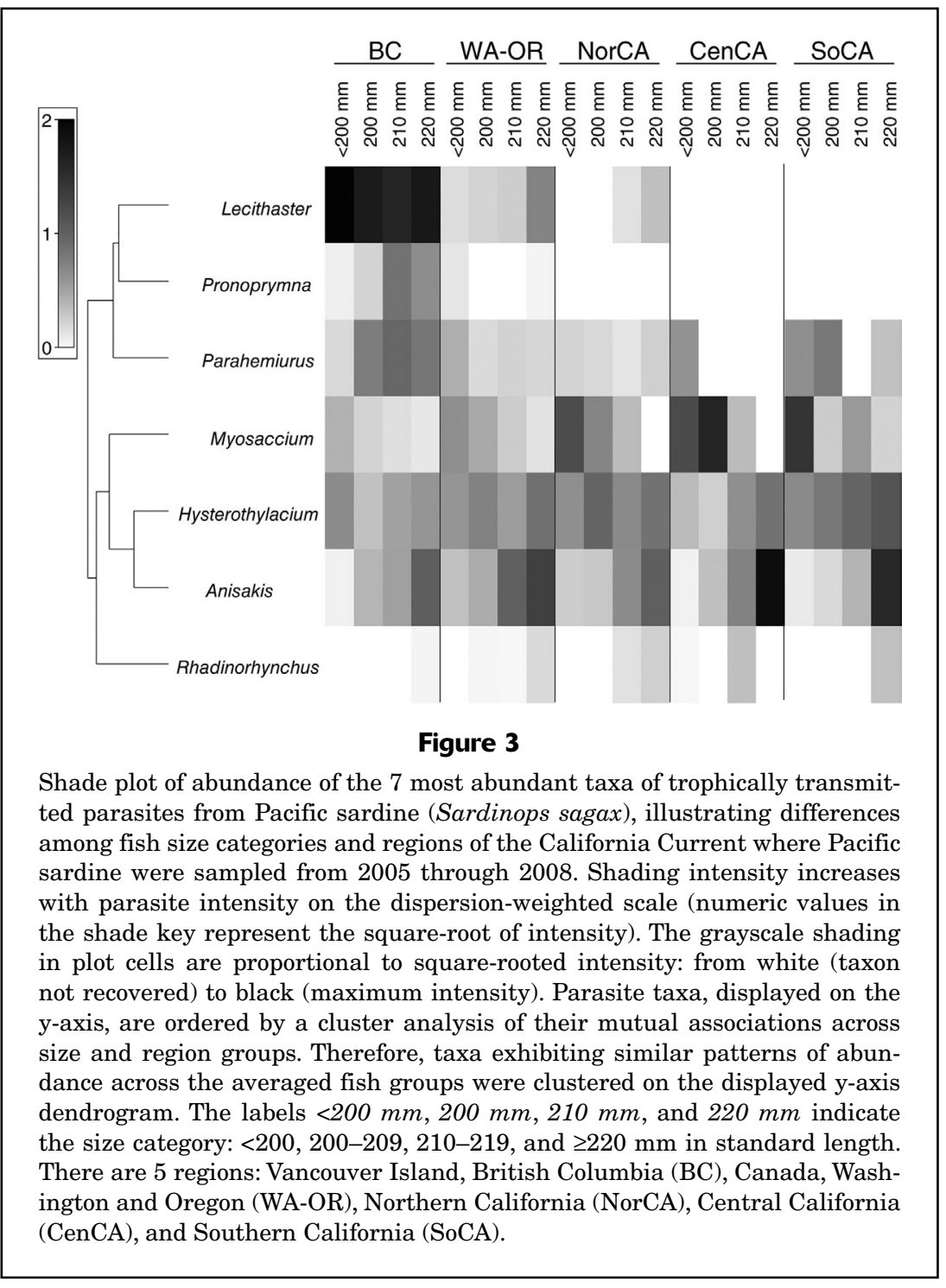

$35.9 \%$ and $40.5 \%$ in the 2 larger size categories. This parasite contributed $85.3 \%$ to the parasite communities of northern anchovy collected off Grays Harbor, and the high contribution of this parasite was responsible for the high similarity among these northern anchovy and the Pacific sardine from British Columbia.

In contrast to the Pacific sardine caught off British Columbia, Pacific sardine 210-219 $\mathrm{mm}$ SL and $\geq 220 \mathrm{~mm}$ SL caught off Washington and Oregon and in the regions off California had parasite communities dominated by nematodes. Anisakis spp. contributed over 50\% to the parasite communities in both size categories of large Pacific sardine in all regions south of British Columbia. The only exception was that Pacific sardine 210-219 mm SL from Southern California were dominated by the nematode Hysterothylacium sp. (51.5\% contribution) and the trematode $M$. ecaude ( $48.4 \%$ contribution).

The parasite communities from small (<210 mm SL) Pacific sardine from Washington and Oregon and northern anchovy collected off Willapa Bay were also dominated by Hysterothylacium sp. (44.5\% and $62.6 \%$ contribution, respectively). In contrast, the small Pacific sardine collected off all regions of California were dominated by $M$. ecaude. The one exception was that Pacific sardine $<210 \mathrm{~mm}$ SL from Southern California were dominated by another trematode, $P$. merus (63.2\% contribution). The high abundance 
of $P$. merus in this size category made them cluster with the northern anchovy from Southern California, where P. merus had a $31.2 \%$ contribution to the parasite community.

\section{Discussion}

\section{Regional comparisons}

The paradigm that when the northern stock of Pacific sardine is large and ocean conditions are favorable all Pacific sardine $>200 \mathrm{~mm}$ SL, or some other length, migrate to northern waters and then all return to Central and Southern California seasonally each year to spawn may no longer be supported. We found that Pacific sardine were not uniformly infected with the same trophically transmitted parasite communities throughout the CCS, indicating that not all Pacific sardine of the northern subpopulation made the complete round-trip migration during the years studied. The parasite communities of all size categories of Pacific sardine collected off British Columbia were more similar to each other than to all sizes collected from any other region. The correct allocation in the CAP analysis of $70-80 \%$ of these parasite communities to British Columbia indicates that, during the years studied, a large proportion of Pacific sardine in British Columbia remained as residents, not returning to Central or Southern California to spawn. Differences among parasite communities from the region off Washington and Oregon and the 3 regions in California were not statistically significant, although a north-south trend was apparent in the nonmetric MDS plot (Fig. 2A).

Several taxa of parasites contributed to differences in the parasite communities among regions and size categories of Pacific sardine. Among these, the trematode L. gibbosus was recovered primarily off British Columbia from all sizes of Pacific sardine and not from any sardines examined from Central and Southern California. In contrast, the trematode $M$. ecaude was recovered in greatest abundances in small Pacific sardine from California regions and only from $5 \%$ of Pacific sardine collected in British Columbia. The parasite communities recovered from California regions also had higher abundances of the nematode Hysterothylacium sp. than those collected off British Columbia. Distinct distributional patterns of these parasites indicate that not all Pacific sardine of the northern stock make an annual roundtrip migration connecting the terminal regions of their habitat.

Regional differences in the parasite communities of Pacific sardine are supported by observed regional differences among parasite communities of northern anchovy. This other small, pelagic species generally harbors parasite species known to infect the Pacific sardine (Love and Moser, 1983), and, as a non-migratory species (Bakun, 1996), northern anchovy should host parasite species present in a local geographical area. We found a significant difference among the parasite communities of all 3 northern anchovy collections, a finding that agrees with the distributions of parasites recovered from Pacific sardine. The parasite community of northern anchovy collected from Grays Harbor had high similarity to those of Pacific sardine from British Columbia and supported a restricted northern distribution of L. gibbosus in the CCS. The northern anchovy from Southern California (part of the central subpopulation of northern anchovy) had a higher prevalence of Hysterothylacium sp., similar to the Pacific sardine collected there.

\section{Parasites as biological tags}

Parasite life span and life history are important considerations for selecting parasite taxa as biological tags (MacKenzie and Abaunza, 1998, 2014). The parasite communities of Pacific sardine in this study included both long-lived nematodes and shorter-lived trematodes. The maximum life span of the trematode L. gibbosus was reported to be 1-9 months in pink (Oncorhynchus gorbuscha) and chum (O. keta) salmon captured off central British Columbia (Margolis and Boyce, 1969). We recovered both mature and immature $L$. gibbosus in Pacific sardine off British Columbia from March through November, but we recovered none off Southern California, not even among April samples that were thought to include returns from British Columbia. The complete absence of $L$. gibbosus in our samples of large Pacific sardine caught off Southern California could be interpreted 3 ways: 1) our samples from Southern California were not representative of the Pacific sardine in the region at the time, 2) Pacific sardine did not return from British Columbia to Southern California, or 3) the life span of L. gibbosus is too short to be recovered after a return migration south. However, given that some of the L. gibbosus specimens recovered off British Columbia in November were still immature, their life span would have to be less than 5-6 months if this was the only reason for their absence from Pacific sardine caught in Southern California the following April.

The other trematode that contributed to differences in parasite communities among regions was $M$. ecaude. Unfortunately, little information is available on the distribution and life history of this species in the CCS. However, we have confidence that this trematode and L. gibbosus have sufficiently long life spans to evaluate seasonal movements of their fish hosts. In the CCS, $M$. ecaude has been previously reported from Pacific sardine caught off Baja California, Mexico (Sánchez-Serrano and Cáceres-Martínez, 2017), off Southern California (Montgomery, 1957; Kunnenkeri, 1962), and off southern Oregon (Jacobson et al., 2012). These reports and our observations of the high abundance of this parasite in small Pacific sardine in Central and Southern California compared to other regions and size classes of Pacific sardine suggest that the southern region of the CCS is likely the primary region of parasite transmission. However, the recovery of $M$. ecaude from a small percentage of Pacific sardine $<200 \mathrm{~mm}$ SL caught off British Columbia (9\%) and off Washington and Oregon 
(10\%) indicates that either transmission of the parasite occurs on a small scale in northern regions of the CCS or a very small number of Pacific sardine $<200 \mathrm{~mm}$ SL made the migration north. Moreover, the recovery of only 7 Pacific sardine infected with both $L$. gibbosus and $M$. ecaude and of only 3 Pacific sardine $\geq 200 \mathrm{~mm}$ SL in Northern California infected with $L$. gibbosus indicates that a complete migration to and from British Columbia, or even Washington and Oregon, for all migratorysize Pacific sardine did not occur during the years of our study.

Other parasites recovered from Pacific sardine that contributed to differences among regions include the nematodes and the acanthocephalan that are both longlived taxa. For example, Anisakis nematodes, which mature in cetaceans, accumulate as long-lived larvae in fish intermediate hosts and have been successfully used as biological tags for many fish populations (MacKenzie, 2002; Mattiucci et al., 2008; Mattiucci and Nascetti, 2008). In our study, there was also a greater abundance of Anisakis spp. in large Pacific sardine recovered off Central and Southern California, possibly because of a greater abundance of the definitive whale hosts in these regions of the CCS (Calambokidis and Barlow, 2004). Genetic identification of larval anisakids from a subset of Pacific sardine used in our study revealed a panmictic distribution of 3 populations of Anisakis spp., but these populations could not help inform stock structure or migration behavior of Pacific sardine in the CCS (Baldwin et al., 2011). The acanthocephalan Rhadinorhynchus trachuri, also longer-lived than the trematodes, is known to be a parasite of offshore fish species (GeorgeNascimento, 2000; Jacobson et al., 2012). Although less commonly recovered than the nematodes, it was recovered more often from the large Pacific sardine caught south of British Columbia. Its low abundance in large Pacific sardine from British Columbia indicates that fewer of these fish had been offshore compared with those from other regions, another line of evidence for residency in waters of British Columbia.

The spatial distributions of parasites in marine fish species have often reflected large geographical patterns such as latitudinal gradients (Blaylock et al., 1998; González and Poulin, 2005; González et al., 2006). A combination of environmental gradients and dispersal limitation of hosts and different developmental stages of parasites contribute to the latitudinal distribution of marine parasites (Oliva and González, 2005; González et al., 2006; González et al., 2008; Timi et al., 2010). For Pacific halibut (Hippoglossus stenolepis), a general north-south cline of parasite species distributions has been described from the Aleutian Islands, Alaska, to Northern California (Blaylock et al., 1998). Separate stocks of Pacific halibut, with some overlapping migration patterns, were confirmed by using their parasite communities, but one continuous stock was identified south of the Queen Charlotte Islands of British Columbia (Blaylock et al., 2003). Similarly, in our study, the distributional patterns of parasites showed high residency in British Columbia and an overlapping migration pattern for Pacific sardine south of British Columbia with a potential latitudinal gradient (Fig. 2A).

In the eyes of fish collected off South Africa, where this species is known as the South African sardine, Weston et al. (2015) found a significant difference in the abundance of a "tetracotyle" type larval trematode, tentatively identified as Cardiocephaloides sp. (Reed et al., 2012), and that difference supports the existence of a putative western and a putative southern stock with some degree of mixing. After 6 years of continuous data on the prevalence of this larval trematode from the west and south coasts of South Africa, de Moor et al. (2017) fit a sardine stock assessment model directly to parasite prevalence-by-length data and found that this inclusion of parasitological data improved estimates of annual movement and mixing between these semi-discrete stocks.

\section{Migration north}

Following the early tagging studies (Clark and Janssen, 1945), it has been assumed that Pacific sardine $\geq 200 \mathrm{~mm}$ SL, which are capable of migrating (Lo et al., 2011), migrate north from Southern California in the spring when ocean conditions in the north are favorable. We found no significant differences between the parasite communities of Pacific sardine $<200 \mathrm{~mm}$ SL and those of Pacific sardine 200-209 $\mathrm{mm} \mathrm{SL}$, indicating that there is not a clear cut off at $200 \mathrm{~mm}$ SL at which a Pacific sardine will migrate. A recent paper by $\mathrm{McDaniel}$ et al. (2016) that included size and age data for Pacific sardine from British Columbia, Oregon and Washington, and Central and Southern California during 1981-2010 described a pattern of increasing age at length with distance from Southern California. They concluded that their results provide evidence that the migration of the northern subpopulation of the Pacific sardine to the northern reaches of their range in summer is age based, instead of length based.

Sardine biomass and length data from surveys that combined data from acoustic and trawl sampling and were conducted in the spring and summer of 2008 indicate that most, if not the entire, northern stock of Pacific sardine migrated from offshore waters of Southern California to inshore waters of the PNW and British Columbia (Demer et al., 2012). Unfortunately, we did not collect Pacific sardine from British Columbia in 2008 , but our results from other years do not support the conclusion that the entire stock migrates that far north. Although our parasite community analysis was suggestive of a statistically significant difference only between the Washington and Oregon region and the Central California region for Pacific sardine $<210 \mathrm{~mm}$ SL (pairwise PERMANOVA: $P=0.06$ ), the greater abundance of M. ecaude in Pacific sardine $<210 \mathrm{~mm} \mathrm{SL}$ in all California regions compared with that of the Pacific sardines from Washington and Oregon (Fig. 3) indicates that a proportion of Pacific sardine up to $210 \mathrm{~mm}$ SL may remain as residents in their natal regions. In addition, our samples of Pacific sardine $\geq 220 \mathrm{~mm}$ SL caught off Central and 
Southern California in the spring had a greater abundance of the long-lived nematodes Hysterothylacium sp. and Anisakis spp. than those caught off Washington and Oregon and British Columbia in summer and fall. If the entire biomass of large Pacific sardine were migrating north, we would have expected to see the same abundance of these long-lived parasites throughout the CCS.

\section{Return migration south}

Lo et al. (2011) estimated different length-specific migration rates in 2003-2005 between the PNW and California and estimated that close to $50 \%$ of Pacific sardine 200 $210 \mathrm{~mm}$ SL and close to $100 \%$ of Pacific sardine $\geq 220 \mathrm{~mm}$ SL migrated back to California in the fall and winter of 2003 and 2004. Similar to our conclusions, they questioned whether fish $<200 \mathrm{~mm}$ SL remained as residents in the PNW because they had only weak evidence that some of these small fish returned to California. They concluded that not all Pacific sardine migrate and that some stay in the PNW and California (their study did not include British Columbia). Our results indicate that a high proportion of Pacific sardine of all size classes remained in waters of Canada during the period of our study and that waters off Washington and Oregon could be an area of mixing between regions for large Pacific sardine but could also support local recruitment.

In the McDaniel et al. (2016) study, Pacific sardine from British Columbia and from Oregon and Washington collected from July through December were older than those from Central and Southern California. They did not have data from January through March, and age and length data from April through June were presented only for California catches, but the ages of the largest and oldest Pacific sardine from California at all seasons were still younger than those from Oregon and Washington and from British Columbia. Although they state that their work assumed a single migrating population and that subpopulation structure could compromise their results of an age-based migration, they do not account for the difference in maximum ages between locations except for the unlikelihood of gear selectivity or different aging techniques. Our results indicate not only that they could indeed have documented age-based migration but also that their results could additionally reveal residency of fish in northern regions of the CCS, in contrast to the notion of a single migrating population. Similarly, Dorval et al. (2015) reported a reduction in the size distribution of Pacific sardine caught off California during 2005-2010 compared with that in 1996-2004. The larger size classes (250 and $260 \mathrm{~mm} \mathrm{SL}$ ) present in the survey conducted in spring 2004 off California were not recorded again during the 2005-2010 survey (Dorval et al., 2015). They speculated that Pacific sardine $>250 \mathrm{~mm}$ SL that did not return after a northern migration either remained in the north or were removed by fishing. These observations are not the first to suggest overwintering of Pacific sardine in northern regions of the CCS, as spawning had previously been reported in 1998 and 2004 in waters of
Canada (McFarlane et al., 2005) and during 1994-1998 and 2003-2004 in the PNW (Bentley et al., 1996; Emmett et al., 2004).

\section{Management implications}

Migration rates (the percentages of the population moving into other regions) are an important factor for managing transboundary fish stocks like the northern stock of Pacific sardine. Schweigert et al. ${ }^{5}$ estimated annual migration rates to British Columbia on the basis of differences in biomass of Pacific sardine caught during surveys conducted off the west coast of Vancouver Island and the total biomass estimate for the coast-wide population as presented by Hill et al. ${ }^{6}$ in the annual U.S. sardine assessment. During the years of our study, Schweigert et al. ${ }^{5}$ estimated an average migration rate of $27.2 \%$ in 2006 and $34.7 \%$ in 2008 . Their survey was not conducted in 2007 , and in 2005 it was an incomplete survey from which they estimated a $13.2 \%$ annual migration rate. The significant differences among parasite communities of Pacific sardine from British Columbia and of those from all other regions indicate that the relatively large biomass $\left(>200,000\right.$ metric tons, Schweigert et al. $\left.{ }^{5}\right)$ found off the coast of Vancouver Island in those years consisted of a large proportion of Pacific sardine that remained as residents of British Columbia waters as well as migrants from the southern regions.

The examination of allozymes among Pacific sardine from regions of Mexico and California (Hedgecock et al., 1989) and of mitochondrial DNA throughout the CCS (Lecomte et al., 2004) and among Mexican regions (García-Rodríguez et al., 2011) provides evidence for no genetic stock structure in the CCS. However, although Lecomte et al. (2004) state that their mitochondrial DNA data support a basin modal for the Pacific sardine in which a species distribution contracts to a central optimal range during population crashes, they also state that on shorter time scales local recruitment may dominate. At this time, our parasite data from Pacific sardine cannot provide quantitative information on migration rates, nor do they indicate distinct stock structure, but they do elucidate patterns of migration, residency, and periodic local recruitment and indicate that a greater variability in annual migratory behavior of Pacific sardine should be considered. A holistic inclusion of multidisciplinary approaches and techniques (as reviewed in Baldwin et al., 2012; Catalano et al., 2014; Pita et al., 2016) that advances our understanding of economically and ecologically important species should improve management of Pacific sardine, even in the

\footnotetext{
${ }^{5}$ Schweigert, J., G. McFarlane, and V. Hodes. 2010. Pacific sardine (Sardinops sagax) biomass and migration rates in British Columbia. Dep. Fish. Oceans, Can. Sci. Advis. Secr. Res. Doc. 2009/088, 13 p. [Available from website.]

${ }^{6}$ Hill, K. T., E. Dorval, N. C. H. Lo, B. J. Macewicz, C. Show, and R. Felix-Uraga. 2008. Assessment of the Pacific sardine resource in 2008 for U.S. management in 2009, 147 p. Agenda item G.2.b., Suppl. attach. 1. Pacific Fish. Manage. Counc., Portland, OR. [Available from website.]
} 
absence of genetically distinct stock isolation. Examination of multiple biological metrics of Pacific sardine with testing of habitat prediction models should help elucidate migration patterns and improve estimates of migration. A new perspective of greater interannual and seasonal variability in behavior of Pacific sardine will also likely benefit future research efforts and fisheries management.

\section{Acknowledgments}

We dedicate this manuscript to our inspirational coauthor and good friend B. Emmett, who lost a battle against cancer prior to publication. We thank, for their assistance, individuals from the NOAA Northwest and Southwest Fisheries Science Centers, Oregon State University, the Scripps Institution of Oceanography, Fisheries and Oceans Canada, and the Pacific sardine fishing industry. Funding was provided by the National Marine Fisheries Service and by the Mamie Markham Research and Walter G. Jones Fisheries Development Awards to R. Baldwin.

\section{Literature cited}

Anderson, M. J.

2001. A new method for non-parametric multivariate analysis of variance. Austral Ecol. 26:32-46. Crossref

Anderson, M. J., and J. Robinson.

2003. Generalized discriminant analysis based on distances. Aust. N.Z. J. Stat. 45:301-318. Crossref

Anderson, M. J., R. N. Gorley, and K. R. Clarke.

2008. PERMANOVA+ for PRIMER: guide to software and statistical methods, 214 p. PRIMER-e, Plymouth, UK.

Arthur, J. R., and E. Albert.

1994. A survey of the parasites of Greenland halibut (Reinhardtius hippoglossoides) caught off Atlantic Canada, with notes on their zoogeography in this fish. Can. J. Zool. 72:765778. Crossref

Bakun, A.

1996. Patterns in the ocean: ocean processes and marine population dynamics, 323 p. Calif. Sea Grant Coll. Syst., Univ. Calif., La Jolla, CA.

Baldwin, R. E., and C. P. Goater.

2003. Circulation of parasites among fishes from lakes in the Caribou Mountains, Alberta, Canada. J. Parasitol. 89:215225. Crossref

Baldwin, R. E., T. W. Miller, R. D. Brodeur, and K. C. Jacobson. 2008. Expanding the foraging history of juvenile Pacific salmon: combining stomach-content and macroparasitecommunity analyses for studying marine diets. J. Fish Biol. 72:1268-1294. Crossref

Baldwin, R. E., M. B. Rew, M. L. Johansson, M. A. Banks, and

K. C. Jacobson.

2011. Population structure of three species of Anisakis nematodes recovered from Pacific sardines (Sardinops sagax) distributed throughout the California Current System. J. Parasitol. 97:545-554. Crossref

Baldwin, R. E., M. A. Banks, and K. C. Jacobson.

2012. Integrating fish and parasite data as a holistic solution for identifying the elusive stock structure of Pacific sardines (Sardinops sagax). Rev. Fish Biol. Fish. 22:137-156. Crossref
Bentley, P. J., R. L. Emmett, N. C. H. Lo, and H. G. Moser.

1996. Egg production of Pacific sardine (Sardinops sagax) off Oregon in 1994. CalCOFI Rep. 37:193-200.

Blaylock, R. B., L. Margolis, and J. C. Holmes.

1998. Zoogeography of the parasites of Pacific halibut (Hippoglossus stenolepis) in the northeast Pacific. Can. J. Zool. 76:2262-2273. Crossref

2003. The use of parasites in discriminating stocks of the Pacific halibut (Hippoglossus stenolepis) in the northeast Pacific. Fish. Bull. 101:1-9.

Bray, J. R., and J. T. Curtis.

1957. An ordination of the upland forest communities of southern Wisconsin. Ecol. Monogr. 27:325-349. Crossref

Bush, A. O., K. D. Lafferty, J. M. Lotz, and A. W. Shostak.

1997. Parasitology meets ecology on its own terms: Margolis et al. revisited. J. Parasitol. 83:575-583. Crossref

Calambokidis, J., and J. Barlow.

2004. Abundance of blue and humpback whales in the eastern North Pacific estimated by capture-recapture and line-transect methods. Mar. Mamm. Sci. 20:63-85. Crossref

Catalano, S. R., I. D. Whittington, S. C. Donnellan, and B. M. Gillanders.

2014. Parasites as biological tags to assess host population structure: guidelines, recent genetic advances and comments on a holistic approach. Int. J. Parasitol: Parasites Wildl. 3:220-226. Crossref

Clark, F. N., and J. F. Janssen.

1945. Movements and abundance of the sardine as measured by tag returns. In Results of tagging experiments in California waters on the sardine (Sardinops caerulea). Calif. Dep. Fish Game, Fish Bull. 61, p. 7-42. [Available from website].

Clarke, K. R., and R. H. Green.

1988. Statistical design and analysis for a 'biological effects' study. Mar. Ecol. Prog. Ser. 46:213-226.

Clarke, K. R., and R. N. Gorley.

2015. PRIMER v7: user manual/tutorial, 296 p. PRIMER-e, Plymouth, UK.

Clarke, K. R., P. J. Somerfield, and M. G. Chapman.

2006. On resemblance measures for ecological studies, including taxonomic dissimilarities and a zero-adjusted Bray-Curtis coefficient for denuded assemblages. J. Exp. Mar. Biol. Ecol. 330:55-80. Crossref

Clarke, K. R., R. N. Gorley, P. J. Somerfield, and R. M. Warwick.

2014a. Change in marine communities: an approach to statistical analysis and interpretation, $3^{\text {rd }}$ ed., 260 p. PRIMER-e, Plymouth, UK.

Clarke, K. R., J. R. Tweedley, and F. J. Valesini.

$2014 \mathrm{~b}$. Simple shade plots aid better long-term choices of data pre-treatment in multivariate assemblage studies. J. Mar. Biol. Assoc. U.K. 94:1-16. Crossref

Cury, P., A. Bakun, R. J. M. Crawford, A. Jarre, R. A. Quiñones, L. J. Shannon, and H. M. Verheye.

2000. Small pelagics in upwelling systems: patterns of interaction and structural changes in "wasp-waist" ecosystems. ICES J. Mar. Sci. 57:603-618. Crossref

de Moor, C. L., D. S. Butterworth, and C. D. van der Lingen.

2017. The quantitative use of parasite data in multistock modelling of South African sardine (Sardinops sagax). Can. J. Fish. Aquat. Sci. 74:1895-1903. Crossref

Demer, D. A., J. P. Zwolinski, K. A. Byers, G. R. Cutter, J. S. Renfree, T. S. Sessions, and B. J. Macewicz.

2012. Prediction and confirmation of seasonal migration of Pacific sardine (Sardinops sagax) in the California Current Ecosystem. Fish. Bull. 110:52-70. 
Dorval, E., J. D. McDaniel, B. J. Macewicz, and D. L. Porzio.

2015. Changes in growth and maturation parameters of Pacific sardine Sardinops sagax collected off California during a period of stock recovery from 1994 to 2010. J. Fish Biol. 87:286-310. Crossref

Emmett, R. L., R. D. Brodeur, and P. M. Orton.

2004. The vertical distribution of juvenile salmon (Oncorhynchus spp.) and associated fishes in the Columbia River plume. Fish. Oceanogr. 13:392-402. Crossref

Emmett, R. L., R. D. Brodeur, T. W. Miller, S. S. Pool, P. J. Bentley,

G. K. Krutzikowsky, and J. McCrae.

2005. Pacific sardine (Sardinops sagax) abundance, distribution, and ecological relationships in the Pacific Northwest. CalCOFI Rep. 46:122-143.

García-Rodríguez, F. J., S. A. García-Gasca, J. De La Cruz-Agüero, and V. M. Cota-Gómez.

2011. A study of the population structure of the Pacific sardine Sardinops sagax (Jenyns, 1842) in Mexico based on morphometric and genetic analyses. Fish. Res. 107:169-176. Crossref

George-Nascimento, M.

2000. Geographical variations in the jack mackerel Trachurus symmetricus murphyi populations in the southeastern Pacific Ocean as evidenced from the associated parasite communities. J. Parasitol. 86:929-932. Crossref

González, M. T., and R. Poulin.

2005. Nested patterns in parasite component communities of a marine fish along its latitudinal range on the Pacific coast of South America. Parasitology 131:569-577. Crossref

González, M. T., C. Barrientos, and C. A. Moreno.

2006. Biogeographical patterns in endoparasite communities of a marine fish (Sebastes capensis Gmelin) with extended range in the Southern Hemisphere. J. Biogeogr. 33:1086-1095. Crossref

González, M. T., R. Vásquez, and E. Acuña.

2008. Biogeographic patterns of metazoan parasites of the bigeye flounder, Hippoglossina macrops, in the Southeastern Pacific coast. J. Parasitol. 94:429-435. Crossref

Hargreaves, N. B., D. M. Ware, and G. A. McFarlane.

1994. Return of Pacific sardine (Sardinops sagax) to the British Columbia coast in 1992. Can. J. Fish. Aquat. Sci. 51:460-463. Crossref

Hart, J. L.

1943. Tagging experiments on British Columbia pilchards. J. Fish. Res. Board Can. 6 b:164-182. Crossref

Hedgecock, D., E. S. Hutchinson, G. Li, F. L. Sly, and K. Nelson.

1989. Genetic and morphometric variation in the Pacific sardine, Sardinops sagax caerulea: comparisons and contrasts with historical data and with variability in the northern anchovy, Engraulis mordax. Fish. Bull. 87:653-671.

Herrick, S. F., J. G. Norton, R. Hannesson, U. R. Sumaila, M. Ahmed, and J. Pena-Torres.

2009. Global production and economics. In Climate change and small pelagic fish (D. Checkley, J. Alheit, Y. Oozeki, and C. Roy, eds.), p. 256-284. Cambridge Univ. Press, New York.

Hill, K. T., N. C. H. Lo, B. J. Macewicz, P. R. Crone, and

R. Felix-Uraga.

2010. Assessment of the Pacific sardine resource in 2010 for U.S. management in 2011. NOAA Tech. Memo. NMFSSWFSC-469, $137 \mathrm{p}$.

Jacobsen, J. A., and L. P. Hansen.

2005. Internal and external tags. In Stock identification methods: applications in fishery science (S. X. Cadrin, K. D. Friedland, and J. R. Waldman, eds.), p. 415-433. Elsevier, Burlington, MA.
Jacobson, K. C., R. E. Baldwin, and D. C. Reese.

2012. Parasite communities indicate effects of cross-shelf distributions, but not mesoscale oceanographic features on northern California Current mid-trophic food web. Mar. Ecol. Prog. Ser. 454:19-36. Crossref

Javor, B.

2013. Do shifts in otolith morphology of young Pacific sardine (Sardinops sagax) reflect changing recruitment contributions from northern and southern stocks? CalCOFI Rep. 54:85-96.

Javor, B., and E. Dorval.

2014. Geography and ontogeny influence the stable oxygen and carbon isotopes of otoliths of Pacific sardine in the California Current. Fish. Res. 154:1-10. Crossref

Javor, B., N. Lo, and R. Vetter.

2011. Otolith morphometrics and population structure of Pacific sardine (Sardinops sagax) along the west coast of North America. Fish. Bull. 109:402-415.

Kunnenkeri, J. K.

1962. Preliminary report on the parasites of the California sardine and the parasitic distribution in Clupeidae. J. Parasitol. 48:149.

Lecomte, F., W. S. Grant, J. J. Dodson, R. Rodríguez-Sánchez, and

B. W. Bowen.

2004. Living with uncertainty: genetic imprints of climate shifts in East Pacific anchovy (Engraulis mordax) and sardine (Sardinops sagax). Mol. Ecol. 13:2169-2182. Crossref

Lo, N. C. H., B. J. Macewicz, and R. L. Charter.

2007. Spawning biomass of Pacific sardine (Sardinops sagax) off California in 2007. NOAA Tech. Memo. NMFSSWFSC-411, $31 \mathrm{p}$.

Lo, N. C. H., B. J. Macewicz, and D. A. Griffith.

2010. Biomass and reproduction of Pacific sardine (Sardinops sagax) off the Pacific northwestern United States, 2003-2005. Fish. Bull. 108:174-192.

2011. Migration of Pacific sardine (Sardinops sagax) off the west coast of the United States in 2003-2005. Bull. Mar. Sci. 87:395-412. Crossref

Love, M. S., and M. Moser.

1983. A checklist of parasites of California, Oregon, and Washington marine and estuarine fishes. NOAA Tech. Rep. NMFS SSRF-777, $576 \mathrm{p}$.

MacKenzie, $\mathrm{K}$.

2002. Parasites as biological tags in population studies of marine organisms: an update. Parasitology 124:153-163. Crossref

MacKenzie, K., and P. Abaunza.

1998. Parasites as biological tags for stock discrimination of marine fish: a guide to procedures and methods. Fish. Res. 38:45-56. Crossref

2014. Parasites as biological tags. In Stock identification methods, $2^{\text {nd }}$ ed. (S. X. Cadrin, L. A. Kerr, and S. Mariani), p. 185-203. Elsevier, London.

Margolis, L., and N. P. Boyce.

1969. Life span, maturation, and growth of two Hemiurid trematodes, Tubulovesicula lindbergi and Lecithaster gibbosus, in Pacific salmon (Genus Oncorhynchus). J. Fish. Res. Board Can. 26:893-907. Crossref

Mattiucci, S., and G. Nascetti.

2008. Chapter 2. Advances and trends in the molecular systematics of anisakid nematodes, with implications for their evolutionary ecology and host-parasite co-evolutionary processes. Adv. Parasitol. 66:47-148. Crossref

Mattiucci, S., V. Farina, N. Campbell, K. MacKenzie, P. Ramos,

A. L. Pinto, P. Abaunza, and G. Nascetti.

2008. Anisakis spp. larvae (Nematoda: Anisakidae) from Atlantic horse mackerel: their genetic identification and 
use as biological tags for host stock characterization. Fish. Res. 89:146-151. Crossref

McDaniel, J., K. Piner, H.-H. Lee, and K. Hill.

2016. Evidence that the migration of the northern subpopulation of Pacific sardine (Sardinops sagax) off the West Coast of the United States is age-based. PLoS ONE 11(11):e0166780. Crossref

McFarlane, G. A., J. Schweigert, L. MacDougall, and C. Hrabok. 2005. Distribution and biology of Pacific sardines (Sardinops sagax) off British Columbia, Canada. CalCOFI Rep. 46:144-160.

Montgomery, W. R.

1957. Studies on digenetic trematodes from marine fishes of $\mathrm{La}$ Jolla, California. Trans. Am. Microsc. Soc. 76:13-36. Crossref

Oliva, M. E., and M. T. González.

2005. The decay of similarity over geographical distance in parasite communities of marine fishes. J. Biogeogr. 32:1327-1332. Crossref

Pita, A., J. Casey, S. J. Hawkins, M. R. Villarreal, M.-J. Gutiérrez,

H. Cabral, F. Carocci, P. Abaunza, S. Pascual, and P. Presa.

2016. Conceptual and practical advances in fish stock delineation. Fish. Res. 173:185-193. Crossref

Radovich, J.

1981. The collapse of the California sardine fishery. In Resource management and environmental uncertainty: lessons from coastal upwelling fisheries (M. H. Glantz and J. D. Thompson, eds.), p. 107-136. John Wiley \& Sons, New York.

Reed, C., K. MacKenzie, and C. D. Van der Lingen.

2012. Parasites of South African sardines, Sardinops sagax, and an assessment of their potential as biological tags.

Rohde, K. Bull. Eur. Assoc. Fish Pathol. 32:41-48.

1984. Zoogeography of marine parasites. Helgol. Meeresunters. 37:35-52. Crossref
Sánchez-Serrano, S., and J. Cáceres-Martínez.

2017. First helminthological record of the Monterey sardine Sardinops sagax from Baja California, Mexico, gathered during two seasons. Hidrobiológica 27:1-11.

Smith, P. E.

2005. A history of proposals for subpopulation structure in the Pacific sardine (Sardinops sagax) population off western North America. CalCOFI Rep. 46:75-82.

Thomas, F., O. Verneau, T. de Meeûs, and F. Renaud.

1996. Parasites as host evolutionary prints: insights into host evolution from parasitological data. Int. J. Parasitol. 26:677-686. Crossref

Timi, J. T., and K. MacKenzie.

2015. Parasites in fisheries and mariculture. Parasitology 142:1-4. Crossref

Timi, J. T., A. L. Lanfranchi, and J. L. Luque.

2010. Similarity in parasite communities of the teleost fish Pinguipes brasilianus in the southwestern Atlantic: infracommunities as a tool to detect geographical patterns. Int. J. Parasitol. 40:243-254. Crossref

Weston, L. F., C. C. Reed, M. Hendricks, H. Winker, and C. D. van der Lingen.

2015. Stock discrimination of South African sardine (Sardinops sagax) using a digenean parasite biological tag. Fish. Res. 164:120-129. Crossref

Wolf, P.

1992. Recovery of the Pacific sardine and the California sardine fishery. CalCOFI Rep. 33:76-86.

Zorica, B., V. Čikes Keč, O. Vidjak, I. Mladineo, and D. Ezgeta Balič.

2015. Feeding habits and helminth parasites of sardine (S. pilchardus) and anchovy (E. encrasicolus) in the Adriatic Sea. Mediterr. Mar. Sci. 17:216-229. Crossref 